\title{
Territórios e Dinâmicas Migratórias nos Açores
}

\author{
Gilberta Pavão Nunes Rocha* \\ Eduardo Ferreira**
}

\begin{abstract}
Resumo: A especificidade de modelos e sistemas que costumam caracterizar a mobilidade dos arquipélagos nas suas várias componentes, fazem com que, em muitos casos, as ilhas possam ser vistas, simultaneamente, como nódulos de atracção, territórios marginais, de tendência marcadamente repulsiva, e espaços onde facilmente os movimentos migratórios se confundem com os de circulação de pessoas, emprestando-lhes uma dinâmica e estrutura demográfica própria.

No caso do arquipélago dos Açores, e como diversas análises já demonstraram, a diversidade das características demográficas das nove ilhas que o compõem, também tem dependido em grande medida, da mobilidade. Assim, o presente artigo pretende apresentar uma perspectiva integrada e de síntese sobre as principais dinâmicas migratórias que caracterizaram o arquipélago e sobre o seu impacte em termos do reforço de um território fragmentado e diverso.
\end{abstract}

Palavras-chave: Migrações; Território; População; Açores.

A mobilidade nas e das ilhas tornou-se numa área de interesse específica para alguns dos campos disciplinares das ciências sociais, constituindo ainda uma das linhas de pesquisa mais importantes dos chamados islands studies (Baldachino, 2004, 2006).

As últimas duas décadas têm sido particularmente profícuas no surgimento de novas perspectivas sobre a relação entre as migrações e os territórios insulares, num esforço continuado, por parte de um conjunto mais ou menos restrito de autores, de chamar a atenção para a especificidade dos modelos e sistemas que caracterizam a mobilidade das ilhas e dos arquipélagos (Baldacchino, 2007; Chapman, 1991; King e Connell, 1999). Como sublinham R. King e J. Connel, numa das obras mais emblemáticas sobre o tema (Small Worlds, Global Lives), as ilhas são, por excelência, "arenas de migração e de mobilidades" (King e Connell, 1999: 2), referindo-se, deste modo, a um quadro mais amplo em que, na maior parte das vezes, o que está em jogo são forças (movimentos populacionais) de natureza e sentidos diversos, a decorrer, simultaneamente, em escalas distintas e envolvendo diferentes grupos de actores migratórios.

Começando pelo seu próprio povoamento, a maior parte dos espaços insulares tem conseguido manter, ao longo dos séculos, uma relação estreita com as migrações. Segundo uma perspectiva mais historicista, a natureza dessa relação, os tipos de fluxo em causa e o aparecimento dos mesmos (de forma isolada ou cíclica) no eixo do tempo longo, podem ser vistos como consequência do papel, mais ou menos diferenciado, que as ilhas foram desempenhando em cada momento da sua história num contexto de permanente ligação com o exterior (Warrington e Milne, 2007). Com efeito, os processos de colonização, as necessidades de defesa militar, as exportações/importações de matérias-primas e de produtos agrícolas ou, mais recentemente, o turismo ou os offshores, explicam, em grande medida, o facto de as ilhas terem conseguido, durante séculos e na maior parte dos casos, manter o estatuto de plataforma privilegiada de uma pluralidade de movimentos migratórios e de circulação de pessoas.

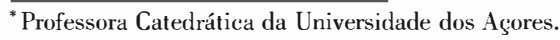

**Assistente da Universidade dos Açores.
} 
Além disso, é importante sublinhar que o contexto onde essas lógicas tende a ser simultaneamente local e global, com causas e consequências endógenas e exógenas. Deste ponto de vista, as ilhas e os arquipélagos, na sua relação com as migrações, deverão ser encarados como interfaces de eleição entre lugares de diferentes escalas e entre processos sócio-espaciais de amplitude distintas, servindo isto, inclusivamente, para questionar a ideia generalizada de que os espaços insulares, pela sua reduzida dimensão e própria condição de descontiguidade territorial, são, muitas vezes, sinónimo de isolamento e de irrelevância social e científica (Anckar, 2006; King, 1999; Ratter e Sandner, 1996). Disso, cremos, o arquipélago açoriano pode ser um bom exemplo, pois:

“... no final de Quatrocentos e primeira metade de Quinhentos, a ocupação humana da periferia açoriana avançava, apesar das dificuldades. Marcos fronteiriços perante o oceano, os Açores iriam desempenhar, pela sua localização, um papel fulcral no apoio à navegação... (Rocha et al., 2005:108)

Ao longo dos séculos e em momentos particulares, nele serviram interesses vários, muitos dos quais associados à posição estratégica do arquipélago no Atlântico, ponto de passagem e apoio de avanços tecnológicos ou de guerras, hoje ainda vivas na memórias de muitos dos seus habitantes" (Rocha et al., 2005: 111)

Dentro do quadro complexo que caracteriza a mobilidade insular, é inegável o papel preponderante da emigração sobre qualquer outro tipo de movimento migratório, sobretudo em ilhas de menor dimensão e com um passado de dependência colonial ${ }^{1}$. A perspectiva económica, frequentemente adoptada no âmbito dos estudos das migrações em espaços insulares, aponta como estando na base desta tendência o facto de as ilhas serem, por norma, espaços economicamente vulneráveis se comparados com outras regiões e Estados dentro do sistema mundial mais amplo. A emigração torna-se, por isso, e na maior parte dos casos, a única saída possível para os problemas advindos quer de um mercado de trabalho limitado, quer do elevado custo de vida que é determinado por uma economia altamente dependente das importações e dos transportes ${ }^{2}$.
Porém, isto não significa, segundo a abordagem em causa, que os territórios de partida sejam forçosamente prejudicados com a solução encontrada por muitos indivíduos e famílias. Como têm vindo a defender alguns autores desde meados da década de oitenta (Bertram e Watters, 1985; Bertram e Poirine, 2007; Oberst e McElroy, 2007), a emigração em massa, nestas condições e a partir de territórios com tais características contribui, em muitas situações, para as ilhas passarem gradualmente a assentar a sua estratégia de desenvolvimento no chamado modelo MIRAB (Migration, Remittances, Aid and Bureaucracy), do qual são componentes principais as remessas e o apoio diverso que é prestado pelos emigrantes, a partir dos países de acolhimento, ao desenvolvimento da sua sociedade de origem. Esta acaba por ser, assim, uma forma de resiliência das ilhas e dos arquipélagos a um conjunto vasto de vulnerabilidades económicas, com um impacte difícil de medir e nem sempre garantido (Fairbairn, 2007).

A perspectiva demográfica sobre os movimentos de saída e a emigração em espaços insulares, por sua vez, tem vindo a dar particular importância aos fenómenos de crescimento populacional nas pequenas ilhas, os quais, fazendo-se acompanhar de alguns desequilíbrios verificados nos sistemas ecológico e produtivo (sobretudo no sistema agrícola), costumam redundar em processos de emigração em massa e de despovoamento do território (King, 1999). Assim, quer a escassez de recursos naturais e económicos em territórios de reduzida dimensão, quer a elevada intensidade dos fluxos de saída constituem factores que estão na origem de importantes inflexões demográficas e de grandes mudanças sociais e económicas. $\mathrm{O}$ que a perspectiva anterior entende ser, de algum modo, uma oportunidade - a emigração e os emigrantes como agentes activos no desenvolvimento dos locais de partida -, a visão sociodemográfica encara como um constrangimento; em função do seu volume e da sua intensidade, os movimentos de saída são perspectivados como podendo interferir negativamente noutras variáveis microdemográficas - como é o caso da natalidade e no esvaziamento e envelhecimento populacional, este último um fenómeno que tem vindo a adquirir particular importância em anos mais recentes, po-

\footnotetext{
${ }^{1}$ Normalmente, as taxas de emigração assumem aí valores mais elevados do que nos países e regiões de matriz continental, mesmo quando falamos de fluxos emigratórios mais específicos como é o caso da saída de camadas qualificadas da população (Docquier e Schiff, 2006; King, 2010).

${ }^{2}$ Factores que, uma vez combinados com algumas determinantes externas importantes, não se encontram à margem das principais causas da emigração açoriana que teve lugar a partir da segunda metade do século XX até finais da década de setenta (Rocha e Ferreira, 2009:186-188).
} 
dendo afirmar-se ser hoje a problemática mais visível das dinâmicas demográficas em todo o mundo.

Perante o panorama menos optimista que esta segunda abordagem analítica apresenta em relação à emigração, os movimentos de entrada surgem, muitas vezes, como um possível contraponto da situação daí resultante. Tanto os fluxos de imigrantes, como os fluxos migratórios de regresso são interpretados como sendo componentes da mobilidade capazes de compensarem, em função das suas condicionantes específicas, algumas assimetrias socioterritoriais, sobretudo aquelas que se encontram assentes em aspectos de ordem demográfica e económica.

As entradas poderão contribuir, assim, e em primeiro lugar, para o reequilíbrio demográfico de certas regiões e locais, não só através do aumento do volume populacional em áreas mais fustigadas pelo despovoamento, mas também para uma possível atenuação das tendências de envelhecimento Por outro lado, os migrantes que entram, se devidamente integrados, poderão vir a oferecer um contributo para a dinamização socioprodutiva a nível local, encontrando-se este potencial bastante dependente de variáveis-chave como a idade, o nível educacional, a inserção sectorial e profissional, o rendimento, as formas de aplicação das poupanças e a distribuição destes efectivos no território.

Normalmente, e no caso concreto dos emigrantes regressados, as repercussões desse contributo tenderão a atingir uma maior amplitude nas situações em que o regresso se processa para as comunidades e os locais de origem e/ou de nascimento, sendo isto particularmente verdadeiro no caso das ilhas, em termos gerais, e, em particular, das ilhas de pequena dimensão (como é o caso de algumas dos Açores), onde a homogeneidade social e o sentimento de pertença prevalecem (King, 2010: 34).

As premissas em que assentam as duas perspectivas acima salientadas fizeram com que alguns autores, como, por exemplo, R. King (1999;2010) tivessem passado a utilizar uma tipologia classificatória dos espaços insulares, na sua relação com os fenómenos migratórios, baseada na dicotomia ilhas nodais vs. ilhas marginais. Como o próprio esclarece, "as ilhas nodais tendem a atrair e enviar população, o que leva à emergência de sociedades cosmopolitas, híbridas e estratificadas (...). Já as ilhas marginais exibem habitualmente uma tendência para a emigração e para o despovoamento, bem como para o síndrome MIRAB" (King, 2010: 42). Apesar da relativa rigidez e do carácter algo simplista do modelo, reconhecidos, desde logo, pelo autor em causa, e que impossibilita que se possa "dar conta da diversidade das ilhas no actual contexto global" (Id., ibid.), encontramos nestas proposições teóricas algum potencial explicativo relativamente às características que muitas ilhas e arquipélagos apresentam enquanto territórios de cruzamento de dinâmicas populacionais e económicas à escala micro e macro. Os Açores tendem a enquadrar-se nesta tipologia.

Uma das características do arquipélago dos Açores é a sua diversidade populacional, associada, em primeiro lugar, à dimensão geográficas das várias ilhas, mas que a ela não se confinam. Ao longo dos tempos e, muito especialmente, durante o século $\mathrm{xx}$, assistimos a uma concentração populacional nas ilhas de maior centralidade histórica e número de habitantes. (Rocha, 1991, 2008) Em 2008, as estimativas apontam para que São Miguel, com mais do dobro dos habitantes da ilha Terceira, tenha conjuntamente com esta cerca de $78 \%$ da população do arquipélago.

\section{Gráfico 1 - Importância relativa da população das ilhas dos Açores em 2008 (\%)}

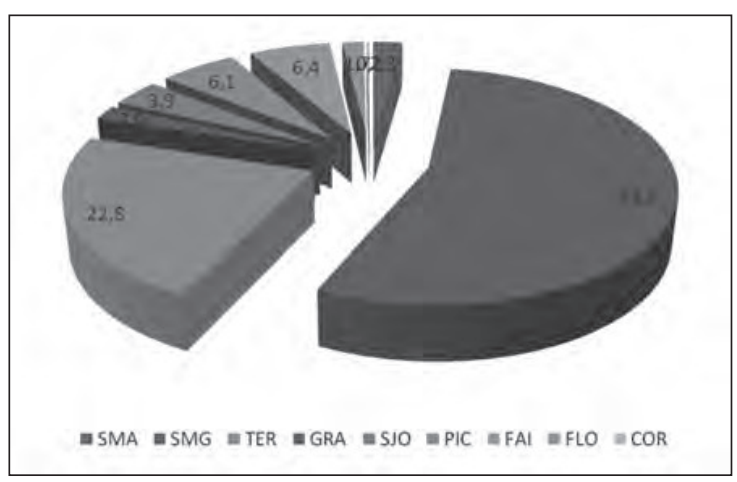

Fonte: SREA, Estimativas da População, 2009.

Centrando-nos na evolução recente, constata-se que a população atravessa, em termos globais, um período de relativa estabilidade, prevendo-se a continuidade do crescimento atenuado observado ao longo dos anos noventa. Durante quase trinta anos, com excepção para a ilha do Corvo, a variação só é positiva nos casos de São Miguel, Terceira e Faial, com decréscimos significativos em Santa Maria, Graciosa, São Jorge e Flores. 


\section{Gráfico 2 - Variação percentual da população dos Açores, por ilha, entre 1981 e 2008}

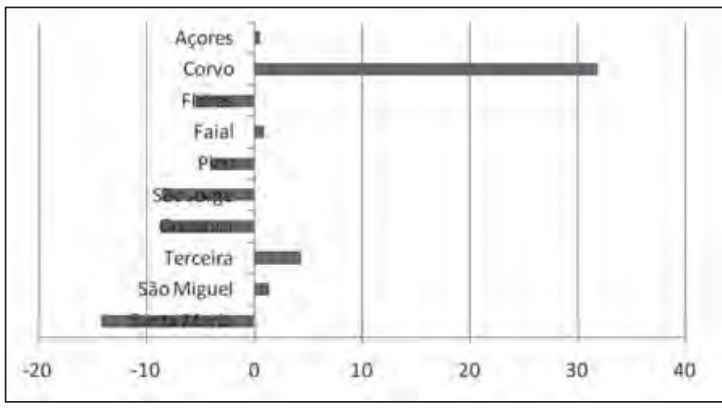

Fonte: INE, Recenseamentos da População de 1981,1991, 2001; SREA, Estimativas da População, 2008.

As diferenças observadas na evolução demográfica são igualmente relevantes no que respeita à ocupação do território, como se pode ver pelas respectivas densidades demográficas. Considerando as Densidades Brutas, destacam-se as ilhas de São Miguel e Terceira, com valores bastante mais elevados do que as restantes (180 e 140 hab/ $/ \mathrm{km} 2$, respectivamente). Seguem-se a Graciosa e o Faial, com quantitativos da ordem dos $80 \mathrm{hab} / \mathrm{km} 2$ e $90 \mathrm{hab} / \mathrm{km} 2$, distinguindo-se ainda bastante das outras ilhas que apresentam valores muito mais baixos. ${ }^{3}$

\section{Gráfico 3 - Densidade populacional bruta} dos Açores, por ilha, em 1981 e 2008

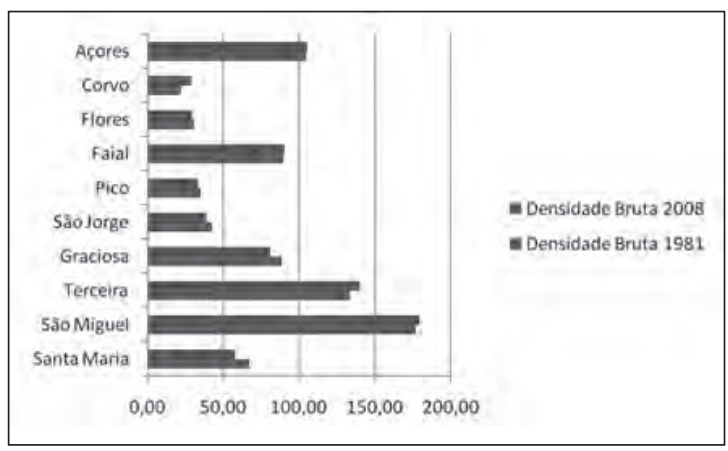

Fonte: INE, Recenseamento Geral da População, 1981; SREA, Anuário Estatístico da Região Autónoma dos Açores, 2008.

A consideração da orografia não deve ser minimizada, embora não sirva como justificação central para grande parte da diversidade encontrada na ocupação do território, acima mencionada, nomeadamente no que respeita a ilhas como Santa Maria e
Graciosa, que têm a maior parte do território abaixo dos 300 metros e que registam, simultaneamente, densidades populacionais bastante baixas.

\section{Gráfico 4 - Orografia das Ilhas}

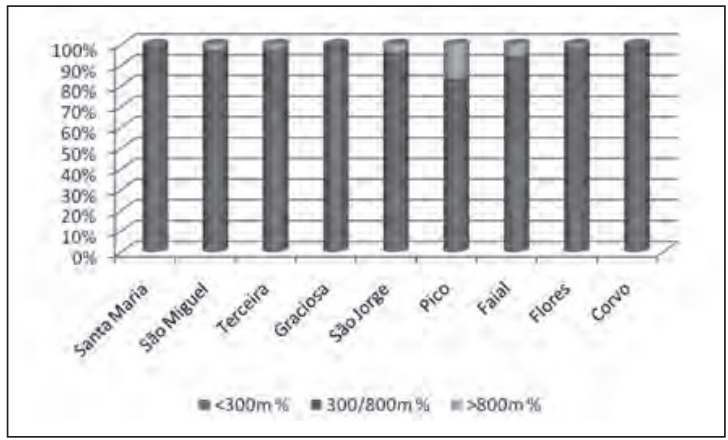

Fonte: SRAM, PROTA.

À continuidade da concentração populacional observada nas ilhas de maior dimensão e mais densamente povoadas não deve ser alheia a dinâmica do movimento natural, também ela dependente de estruturas etárias já contrastantes. A evolução do saldo do movimento natural da globalidade regional apresenta um declínio entre 1991 e 2002, particularmente intenso entre 2000 e 2002 , mas que encontra alguma recuperação a partir desta última data, embora se mantenha com níveis relativamente reduzidos, que variam entre os 400 e os 600 indivíduos (Rocha e Ferreira, 2008). No entanto, algumas ilhas, como a Graciosa, São Jorge e Pico registam saldos naturais negativos no cômputo geral dos anos de 1991 a 2008.

Em função da sua diversidade populacional, da sua configuração geográfica, mas também enquanto parte integrante de um território nacional de matriz continental, os Açores têm sido propícios à combinação de trajectórias migratórias múltiplas e classificáveis em diferentes tipos e escalas: migrações no interior das ilhas (especialmente nas de maior dimensão); migrações inter-ilhas; migrações ilhascontinente e migrações internacionais que coexistem de forma e intensidades diferenciadas ao longo do tempo. A contemporaneidade tem vindo a alterar o sentido da mobilidade representada agora, em grande parte, por fluxos de imigrantes e emigrantes regressados, consubstanciando novos fenómenos

\footnotetext{
${ }^{3}$ A leitura dos valores respeitantes ao Corvo deverá ter em conta a pequenez de efectivos que caracteriza esta ilha.
} 
demográficos e sociais que, assim, substituem a tradicional emigração e, até, movimentos internos que ao longo dos séculos também caracterizaram os giros das gentes açorianas.

Com informações diferenciadas no tempo e com base em estudos com abordagens decorrentes de objectivos distintos, tanto no que respeita à emigração, mas principalmente atendendo à imigração, ao regresso de emigrantes e aos movimentos internos, pensamos poder agora pensar a mobilidade que hoje atravessa os Açores, na linha de R. King, de um modo mais integrado do que aquele que tem vindo a ser adoptado, isto é, pensá-los enquanto variáveis que configuram o conjunto da capacidade de atracção ou repulsão dos territórios açorianos.

No que diz respeito à emigração, verifica-se que esta atinge actualmente níveis bastante baixos, só comparáveis aos observados nas décadas de trinta e quarenta do século $\mathrm{xx}$, pelo que pouco podem contribuir para a futura diversidade demográfica das ilhas, ao contrário do que acontecia no passado (Rocha, 1991; 2008). No entanto, as condicionantes, tanto externas, como internas, entre os dois períodos são bastante distintas. No primeiro caso, não existem hoje restrições à entrada nos países de destino tradicional, o que não acontecia em meados de novecentos, no qual às razões de ordem legislativa (nos EUA) se associavam as dificuldades económicas e sociais decorrentes da Grande Depressão e do conflito mundial. No segundo caso, isto é, numa óptica interna, após a democratização do país e a instauração do regime autonómico, têm vindo a alterar-se, de forma significativa, as características do tecido produtivo e do mercado trabalho regional, aspectos que anteriormente justificavam, em grande parte, os elevados níveis das saídas para os estrangeiro. Estas adquiriram especial intensidade nos anos sessenta e setenta, particularmente entre 1965 e 1975, quando à diminuição da importância do emprego no sector primário, se associaram condições mais favoráveis de entrada e empregabilidade no continente norte-americano. (Rocha e Ferreira, 2008).

\section{Gráfico 5 - Evolução da taxa bruta de emigração entre 1981 e 2007 (\%o)}

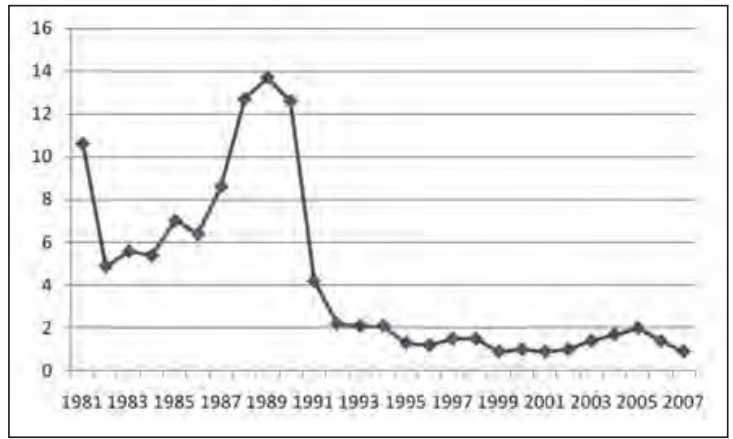

Fonte: SREA, Anuário Estatístico da Região Autónoma dos Açores, vários.

No presente, importa sobretudo ver o resultado que o fenómeno emigratório de décadas e séculos anteriores tem ainda na diversidade da estrutura demográfica e social ou no comportamento cultural das sociedades do arquipélago, embora não seja de negligenciar totalmente as suas novas configurações, desde logo a substituição dos destinos EUA e Canadá, pelo das Bermudas, a sua justificação e motivações, ou até a possibilidade de recrudescimento do fenómeno, como tem vindo a acontecer no continente português.

\section{Gráfico 6 - Taxa de crescimento migratório nos Açores de 1992 a 2008}

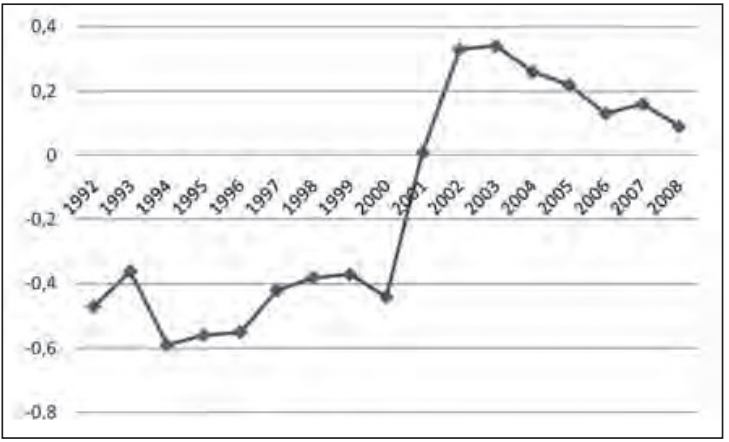

Fonte: SREA, Anuário Estatístico da Região Autónoma dos Açores, vários (cálculos dos autores).

Observando a Taxa de Crescimento Migratório a partir de 1992, quando a Taxa Bruta de Emigração estabiliza a níveis baixos - que no máximo atingem 
os 2\%o -, verifica-se que só no início deste século a tendência se altera, com quantitativos mais elevados nos anos compreendidos entre 2002 e 2004, período em que se assiste a uma combinação dos níveis baixos de saídas com valores significativos de entrada, particularmente de imigrantes. Com efeito, o fenómeno imigratório é bastante recente nos Açores, tendo assumido maior visibilidade estatística e social a partir do final dos anos noventa.

Esta alteração na mobilidade não pode ser dissociada da mudança política, económica e social anteriormente referida, enquadrando-se, de resto, embora com algum desfasamento temporal, na tendência observada a nível nacional. Os países de origem dos imigrantes são, na sua grande maioria, os mesmos que encontramos para a globalidade do país, independentemente de o continente português ser ou não a primeira porta de entrada. O mesmo acontece com as diversas vagas, sendo que foram os africanos os que inicialmente apresentavam maior preponderância, em especial os naturais das ex-colónias portuguesas, designadamente os de Cabo Verde, país que tem um forte relacionamento institucional com os Açores. Seguiram-se os imigrantes da Europa, tanto da União Europeia, como da Europa de Leste e, mais recentemente, do Brasil. (Rocha e outros, 2009)

\section{Gráfico 7 - Evolução do número de estrangeiros residentes nos Açores de 2001 a 2009}

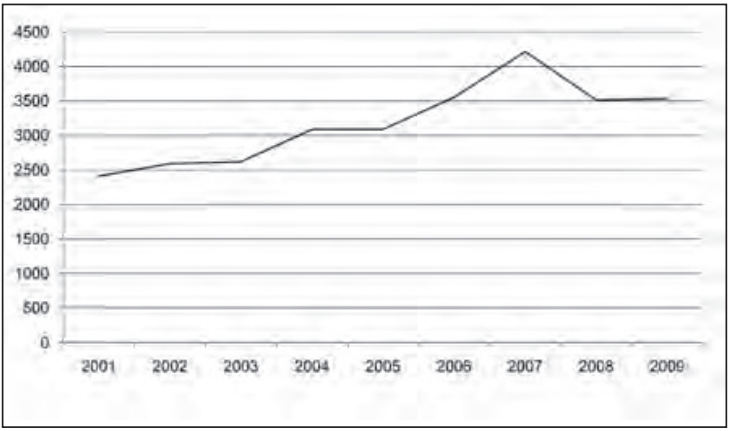

Fonte: SEF, Estatísticas de Estrangeiros, 2001-2009.

Considerando a evolução dos estrangeiros, com autorização de residência, fixados na Região, pode observar-se que o stock aumentou de cerca de 2400 indivíduos, no início da década, para pouco mais de 4200 indivíduos, em 2007, tendo depois conhecido um decréscimo para valores muito semelhantes aos verificados em 2006, ou seja, à volta dos 3500 efectivos.
A desigual repartição desta população pelas nove ilhas que compõem o arquipélago é uma característica marcante do fenómeno imigratório nos Açores, e que se tem mantido ao longo do tempo. S. Miguel, Terceira, Faial e Pico concentraram, desde os finais da década de noventa, os maiores níveis de imigrantes, devido, sobretudo, ao aumento da procura de mão-de-obra verificado no ramo da Construção, quer pelo crescimento que o sector conheceu nessa altura, quer por via do processo de reconstrução resultante do sismo que, em 1998, atingiu uma parte do Grupo Central, nomeadamente as ilhas do Faial, Pico e S. Jorge.

Uma vez terminada essa fase da reconstrução, a importância relativa dos imigrantes nas quatro principais ilhas de acolhimento inicial manteve-se, apesar de, entre si, essa distribuição se ter alterado substancialmente. Com efeito, não só muitos dos estrangeiros que começaram por se fixar no Faial e no Pico rumaram em direcção a S. Miguel e à Terceira - mantendo, portanto, a sua residência na Região -, como estas duas ilhas passaram a ser o destino privilegiado de novos imigrantes vindos directamente dos seus países emissores (Rocha e Ferreira, 2009: 75-91). São, portanto, as ilhas com uma estrutura económica mais sólida e com um mercado de trabalho mais diversificado que, presentemente, conseguem fixar mais de metade desta população (alguns com residência prévia noutras ilhas, outros, vindos directamente do Continente ou de outros países).

Gráfico 8 - Importância relativa de estrangeiros residentes, por ilha, em 2007, 2008 e 2009 (\%)

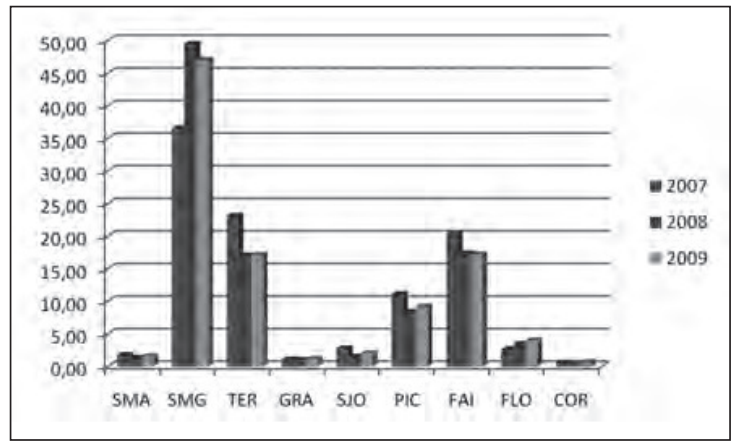

Fonte: SEF, Estatísticas de Estrangeiros, 2007-2009.

Segundo Rocha et al. (2009), apenas 20,0\% e $17,0 \%$ dos inquiridos que responderam ter conhecido o Faial e o Pico, respectivamente, como locais de primeira residência é que vieram inseridos nos 
fluxos posteriores a 2004, sendo os restantes quantitativos referenciáveis a vagas anteriores a esse momento. $\mathrm{O}$ mesmo já não acontece em relação às ilhas de S. Miguel e Terceira, onde cerca de 50,0\% dos imigrantes que se estabeleceram em cada uma delas, foram chegando ao Arquipélago ao longo do período 2005-2008.

\section{Gráfico 9 - Imigrantes segundo o período de chegada aos Açores - São Miguel, Terceira, Faial e Pico (\%)}

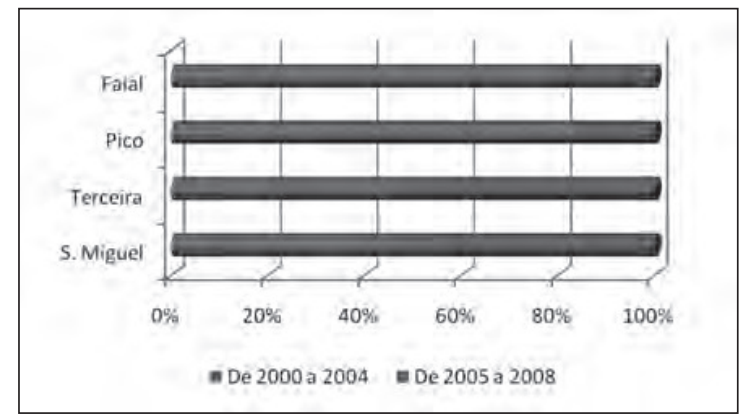

Fonte: Rocha et al. (2009)

\section{Gráfico 10 - Tempo de permanência dos imigrantes nos Açores, por ilha (\%)}

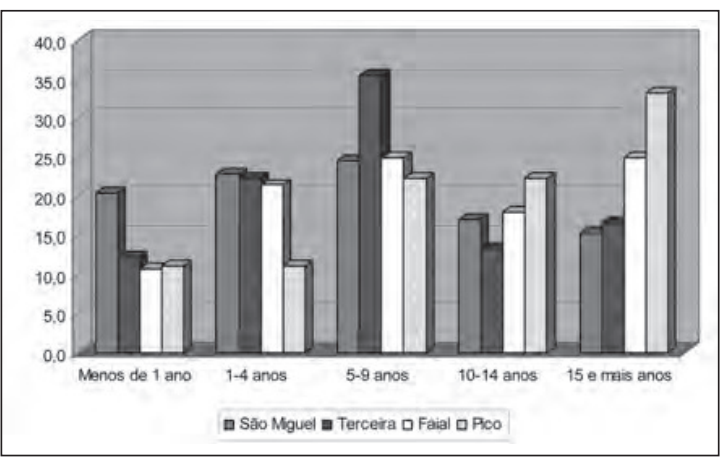

Fonte: Rocha et al. (2009).

Significa isto, ainda, que se as ilhas de menor dimensão, menos densamente povoadas, com maiores declínios populacionais ou, como afirma R. L. Gonçalves, que registam um maior grau de insularidade (Gonçalves, 2010:310) - por exemplo, Santa Maria, Graciosa, São Jorge, Flores e Corvo têm menor capacidade de captar imigrantes, as do Pico e Faial não parecem ter a mesma capacidade de renovação dos fluxos que encontramos na Terceira e, principalmente, em São Miguel.

$O$ poder de atracção diferenciado que estas quatro ilhas apresentam, relativamente à captação de imigrantes vindos directamente do exterior, é de- monstrado também pelo tempo de permanência que cada uma das subpopulações de ilha apresenta. Os maiores contrastes encontram-se entre as ilhas de São Miguel e do Pico, pois enquanto na primeira sobressai uma percentagem significativa de imigrantes que têm um menor tempo de permanência, já na segunda os quantitativos mais elevados respeitam aos que possuem uma residência de maior duração temporal. No Faial as características aproximam-se mais das que observamos no Pico, enquanto a Terceira regista uma situação intermédia, pois se não parece atrair de forma significativa os que se integram nos fluxos mais recentes, também não possui um número relevante dos imigrantes mais antigos.

\section{Gráfico 11 - Importância relativa de estrangeiros residentes na população de cada ilha em 2007 (\%)}

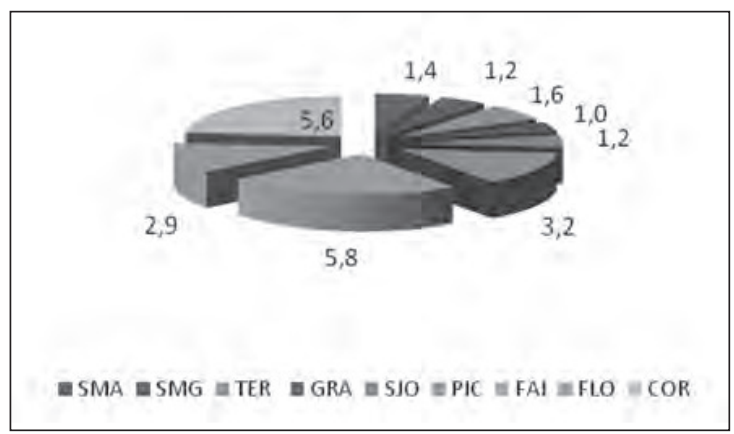

Fonte: SEF, Estatísticas de Estrangeiros, 2007.

No entanto, a importância local das entradas de imigrantes, mesmo que diminutas no contexto regional, representam uma parte mais significativa da população das ilhas de pequena ou média dimensão. Apesar do que anteriormente foi dito relativamente à maior atractividade de São Miguel e Terceira, o valor percentual dos estrangeiros residentes face à globalidade da população é muito menor do que o observado em ilhas como, por exemplo, o Faial ou o Pico em 2007. Assim, à menor atractividade e maior flutuação de imigrantes em algumas ilhas, deve associar-se igualmente as repercussões que em determinados momentos e conjunturas estes poderão ter nas respectivas sociedades.

Toda esta distribuição desigual, do ponto de vista numérico, dos imigrantes pelas várias unidades geográficas faz-se acompanhar de algumas diferenças quanto ao seu perfil. Com efeito, os imigrantes apresentam características relativamente distintas 
em cada uma das quatro ilhas, sendo que a diversidade é mais acentuada entre S. Miguel, por um lado, e Faial e Pico, por outro. Na primeira, verifica-se um maior equilíbrio entre homens e mulheres e também entre os três principais grupos de origem - brasileiros, cabo-verdianos e ucranianos -, sendo que os imigrantes aí fixados se enquadram numa estrutura etária mais jovem, são mais instruídos e desempenham profissões com maior grau de qualificação. Em sentido inverso, no Faial e no Pico há um maior envelhecimento da população imigrante, um maior desequilíbrio entre o número de homens e mulheres, com preponderância daqueles, com níveis de instrução mais baixos e profissões pouco qualificadas (Rocha et al., 2009).

Ainda dentro do quadro dos movimentos migratórios de entrada, consideramos agora o regresso dos emigrantes, um fenómeno relativamente recente na mobilidade açoriana, pelo menos se percepcionado numa óptica de regularidade, contrariamente ao que se passou a nível nacional. Durante todo o século $\mathrm{xX}$ só muito excepcionalmente o encontramos nos Açores e sempre associado a períodos de crise económica nos países de acolhimento, o que não é o caso das últimas décadas. Podemos, assim, pensar que agora pesa essencialmente o factor de atractividade regional, embora no que se refere à capacidade de captação de cada uma das ilhas, o regresso de antigos emigrantes à sua região de origem apresente uma lógica muito menos diferenciada do que a observada nos imigrantes.

\section{Gráfico 12 - Ilha de residência dos emigrantes regressados segundo o local de partida $(\%)$}

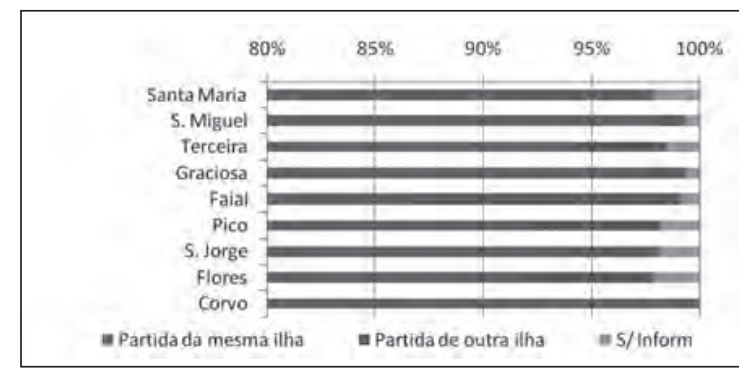

Fonte: Rocha et al. (no prelo).

Com efeito, trata-se de uma população cuja distribuição pelas nove ilhas do arquipélago parece ter vindo a fazer-se desde a década de oitenta, em função, essencialmente, dos territórios de partida, como se pode observar através do Gráfico 11 (Rocha et al., no prelo). Apenas o Faial, o Pico e as Flores concentram uma percentagem de emigrantes regressados originários de outro local superior a $10,0 \%, 0$ que provavelmente pode ser explicado pelo facto de estarmos perante ilhas com uma distância geográfica diminuta em relação a outras, ou seja, ilhas onde a fixação definitiva não implica baixas perspectivas de mobilidade para ilhas vizinhas.

Esta tendência para o retorno aos territórios de partida não é alheia à etapa do ciclo de vida em que se encontra a maior parte dos indivíduos regressados. Na verdade, trata-se de uma população envelhecida, em que mais de $60,0 \%$ têm uma idade superior aos 60 anos e quase metade já saíram da vida activa. Mesmo os cerca de 35,0\% de empregados encontram-se, na sua esmagadora maioria (90,0\%), acima dos 40 anos e desenvolvem uma actividade ligada à pequena agricultura ou ao comércio a retalho, em terras e negócios de família, respectivamente. $\mathrm{O}$ mercado de trabalho, no contexto da distribuição espacial, assume uma importância relativa muito menor do que no caso dos fluxos imigratórios, encontrando-se o grau de atracção das ilhas dependente, sobretudo, dos laços sociais e do sentimento de pertença à comunidade e à ilha de origem.

\section{Gráfico 13 - Emigrantes regressados segundo a situação perante o trabalho e a actividade}

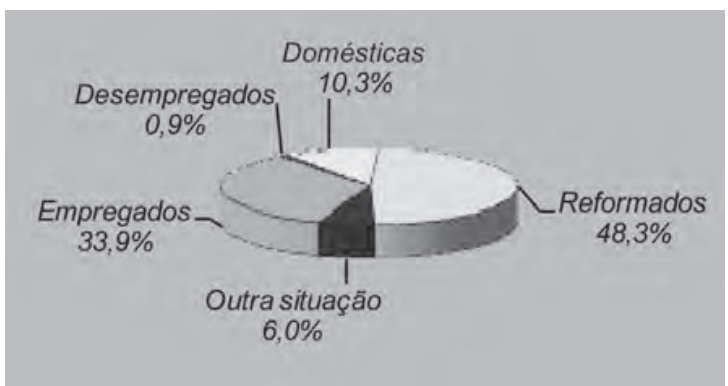

Fonte: Rocha et al. (no prelo).

Quase metade da população inquirida neste âmbito (Rocha et al., no prelo) respondeu que o principal motivo para o regresso aos Açores (depois de um período de permanência no país de acolhimento que, em média, rondou os 15 anos) se prendeu com as saudades que sentiam da terra de partida $(27,0 \%)$ ou com o desejo de passarem a estar mais próximos dos familiares que residiam 
na Região $(21,9 \%)$. O peso relativo destas razões é mais ou menos o mesmo junto daqueles que tiveram uma experiência emigratória mais curta (de, por exemplo, menos de 10 anos), o que somado ainda ao facto de um número bastante significativo destes $(49,3 \%)$ admitir ter regressado devido a dificuldades de adaptação ao país de recepção, indicia assim um regresso generalizado ao ponto em que os emigrantes se encontravam antes da partida, sem grandes níveis de acumulação de conhecimentos profissionais e de capital social. Na sua maioria, voltaram para actividades e profissões idênticas, ou muito semelhantes, às que desempenhavam antes de emigrar (agricultura, construção, reparação de veículos), acreditando-se, por isso, ser muito diminuto o impacte desse retorno ao nível do tecido social e económico dos locais de regresso.

Maior grau de complexidade deverá ser atribuído ao papel que os movimentos internos desempenharam, ao longo das últimas três décadas, nas assimetrias entre ilhas e na capacidade de atracção e de repulsão de cada uma delas. $\mathrm{O}$ conhecimento sobre os fluxos migratórios internos, entre os Açores e o Continente e entre as nove ilhas do Arquipélago, encontra-se limitado, em grande medida, pela inexistência de informação estatística disponível que se torne capaz de sustentar uma análise sociodemográfica mais rigorosa do fenómeno. Todavia, e com base em dados dos últimos três recenseamentos ${ }^{4}$, já foi efectuado algum trabalho neste sentido (Rocha, 1991; Rocha e Ferreira, 2008), o qual acabou por revelar, ainda que recorrendo a indicadores algo grosseiros, algumas pistas acerca da relação estreita entre esta componente específica da mobilidade e as dinâmicas territoriais que têm vindo a marcar os Açores, quer do ponto de vista interno quer na sua relação com o restante território nacional.

Assim, apesar das limitações impostas pela informação disponível, é possível aludir a alguns resultados brutos que são directamente acessíveis pelos volumes de migrantes internos existentes para o total da Região e por concelho, e, a partir daí, dar conta das principais tendências de repul- são ou de atracção populacional manifestadas nas décadas de setenta, oitenta e noventa. À parte disto, desconhecem-se, ainda, a intensidade e o sentido dos fluxos entre ilhas, entre cada uma destas, em específico, e o restante território nacional e entre concelhos da mesma ilha (no caso das de maior dimensão). Do mesmo modo, não se conhece o impacte dos movimentos internos sobre o volume e a estrutura demográfica das populações concelhias e de ilha, ainda que tudo leve a crer que, ao longo do tempo, essa influência tenha sido bastante variável dada a diversidade da dinâmica demográfica das várias ilhas.

Tanto a evolução do número de migrantes internos que, ao longo das últimas três décadas do século passado, se fixaram nos Açores e daí saíram, como a comparação, entre períodos homólogos, dos respectivos saldos migratórios, sugerem que o arquipélago conheceu três fases distintas em termos de mobilidade interna. Observando os períodos de análise mais longos (de 6 anos para as décadas de oitenta e de noventa e de 8 anos para a de setenta), a primeira fase, durante a segunda metade dos anos setenta, é marcada por uma considerável intensidade dos fluxos de entrada e de saída (quase 19000 indivíduos na totalidade), apresentando uma Região mais atractiva do que repulsiva. Uma segunda fase, entre 1985 e 1991, em que, apesar de uma variação diminuta nos valores referentes aos movimentos de saída, se testemunha a diminuição dos quantitativos de entrada (em cerca de 17,0\% aos da década anterior), derivando daí um saldo migratório que, mesmo sendo baixo, é de sinal negativo. A terceira fase, entre 1995 e 2001, dá conta de um aumento significativo do volume de população migrante, a qual, inclusivamente, atinge valores, quer em termos de entradas quer de saídas, superiores aos registados na década de setenta (qualquer uma das componentes ultrapassa os 10000 indivíduos). Porém, esses últimos anos do século Xx mantêm a tendência repulsiva iniciada no decénio anterior.

\footnotetext{
${ }^{4}$ A publicação, a partir do Censo de 1981, de informação respeitante à residência anterior dos indivíduos em dois momentos distintos do período intercensitário, presta-se à aplicação de algumas formas simples de cálculo (métodos directos) na procura de um maior conhecimento acerca das migrações internas. Assim, através da comparação entre dois instantes temporais, e com recurso às categorias Emigrantes do Concelho para outro concelho e Imigrantes no Concelho provenientes de outro concelho, torna-se possível quantificar o número de entradas e de saídas em cada uma das unidades concelhias, de modo a perceber as tendências dominantes (de repulsão ou atracção) em cada uma delas. Para os últimos três períodos intercensitários, as referências temporais da residência anterior dos indivíduos são: para 1970-1981, 31/12/73 e 31/12/79; para 1981-1991, 31/12/85 e 31/12/89; para 1991-2001, 31/12/95 e 31/12/99.
} 


\section{Gráfico 14 - Total de migrantes internos (entradas e saídas) - Açores}

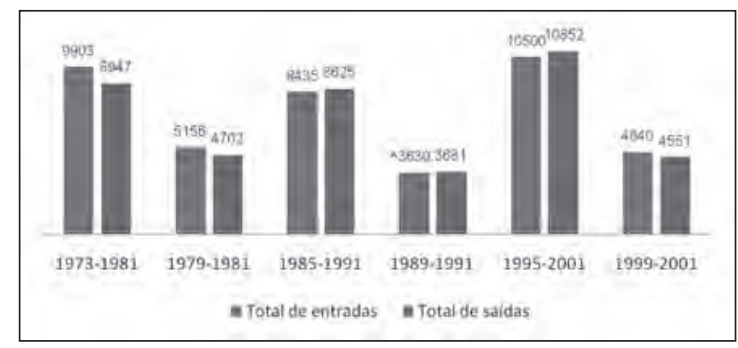

Fonte: INE, Recenseamentos da População, 1981, 1991 e 2001.

\section{Gráfico 15 - Saldo migratório interno - Açores}

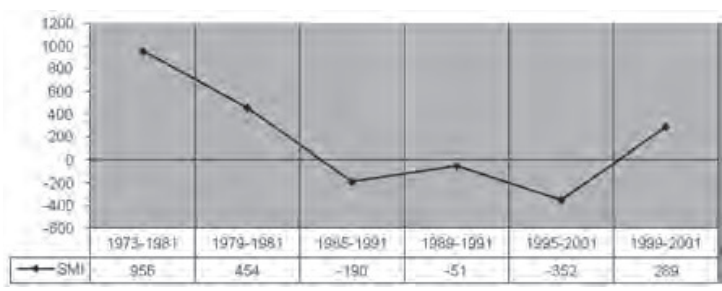

Fonte: INE, Recenseamentos da População, 1981, 1991 e 2001.

Num contexto de esperado crescimento da mobilidade interna podemos verificar que, num intervalo de cerca de trinta anos, os movimentos deste tipo estiveram longe de assumir um carácter de linearidade no tempo, encontrando, de resto, alguma compaginação com o padrão observado a nível nacional. Esta dinâmica poderá constituir um primeiro factor explicativo quer para o volume de migrantes internos que encontramos nos Açores, durante a segunda metade da década de setenta, quer ainda para o grau de atracção demonstrado pela Região ao longo desse período, sobretudo se pensarmos que se tratou de um tempo de necessário arranque e consolidação da Administração Pública regional e dos sistemas de saúde e de ensino, domínios que, nessa altura, careciam ainda de quadros qualificados.

Para além da possibilidade de os Açores poderem ter beneficiado da tendência de repulsão populacional dos principais centros do país, acresce o facto de o período em causa ter sido caracterizado por uma intensa mobilidade de população retornada das ex-colónias, tanto no que se refere aos fluxos de entrada em Portugal continental, como aos movimentos internos, enquadrados em lógicas de mobilidade residencial, que se processaram após essa chegada (Pires et al., 1987). Neste sentido, a vinda de retornados com residência prévia no Continente pode, igualmente, ajudar a explicar uma parte significativa do volume de entradas nos Açores antes de 1981.

Segundo os cálculos efectuados por Pires (2003:206-207), estavam contabilizados como residindo na Região, nessa data, 4515 retornados, isto é, 46,0\% do total de imigrantes internos apurados entre 1973 e 1981 (9903 entradas). Se excluirmos os casos dos ex-residentes nas colónias que possam ter vindo directamente para o Arquipélago - o que não seria de estranhar, uma vez que $3 / 4$ do valor total referido eram naturais das ilhas (id., ibid.) torna-se bastante plausível a hipótese de uma boa parte desses novos residentes da segunda metade da década de setenta serem retornados com "primeira" residência no Continente. Também é provável que muitos tenham chegado aos Açores integrados na lógica de repulsão descrita anteriormente, sobretudo se pensarmos que o perfil educacional e profissional da maioria da população retornada - profissionais liberais, dos serviços e da Administração Pública (Id.: 215) - encaixa nas características daquelas camadas que, a partir dos grandes centros, se dirigiram para as áreas economicamente menos favorecidas.

Ao longo dos anos oitenta, e por referência ao período 1985-91, a Região, comparativamente à década anterior, não só registou a perda de algum poder de atracção, como também não viu aumentado o seu grau de abertura ao restante território nacional por via das saídas. Admitindo a redução da necessidade de quadros vindos do Continente para a Administração Pública Regional, a diminuição dos fluxos de retornados e o facto de, durante a década de oitenta, o sector terciário nos Açores ainda assentar, essencialmente, nos serviços públicos e no pequeno comércio de natureza familiar, compreende-se que essa capacidade de captação de novos residentes tenha conhecido um decréscimo. Em todo o caso, e como revelam alguns dados, apresentados por Peixoto (1998), sobre a caracterização demográfica dos fluxos migratórios inter-regionais (NUTS 3) que tiveram lugar durante o período acima referido, a população que fixa residência nos Açores, entre 1985 e 1991, ainda é composta por uma significativa percentagem de recursos humanos com um nível de qualificação médio e elevado, o que sugere a existência de uma lógica circular de mobilidade de quadros e de pessoal técnico qua- 
lificado entre os Açores e o Continente. Em certa medida, as entradas e saídas nestes grupos tendem a anular-se mutuamente, sendo umas compensadas pelas outras.

A somar ao mercado de trabalho, um outro modo de relação entre estas duas parcelas do território nacional, no que diz respeito aos movimentos internos da população, ao longo do período em análise, terá sido, certamente, a via da educação e da formação, designadamente a da entrada e saída de estudantes da Região por motivos de estudo. Apesar da ausência da variável situação perante o trabalho $e$ a actividade no estudo acima referido, a partir da qual seria possível extrair outro tipo de conclusões em relação a este aspecto, a verdade é que, entre 1985 e 1991, as percentagens de migrantes internos que integram a faixa etária entre os 15 e os 29 anos atingem $38,0 \%$ no caso das saídas e 45,0\% em termos de entradas (id., ibid.:106). Dentro de um contexto nacional, ainda mais ou menos inicial, de acesso generalizado ao Ensino Superior, como era o panorama vivido nos anos oitenta, podemos admitir que, tanto num caso como noutro, deverá estar incluído um volume assinalável de estudantes deslocados do seu local de residência habitual, sendo que, no início dos anos noventa, quase $1 / 4$ do total de alunos da Universidade dos Açores - aproximadamente, 500 estudantes - tinham vindo do Continente ou da Madeira (Diogo et al., 1996: 40).

A terceira fase dos movimentos internos envolvendo os Açores enquanto região de saída e de fixação de população, corresponde, em grande parte, à segunda metade dos anos noventa, e é, como já tivemos oportunidade de observar, distinta das anteriores, sobretudo se olharmos para o volume de efectivos que ultrapassa o limiar dos 20000 indivíduos. Este incremento reflectirá, estamos certos, uma boa parte das mudanças económicas, sociais e territoriais/espaciais por que passou o Arquipélago nas últimas duas décadas do século Xx, anteriormente referidas, ainda que não possamos dissociá-lo de uma tendência bastante mais ampla do ponto de vista territorial ${ }^{5}$.

A referência à mobilidade interna por concelhos permite uma leitura mais detalhada, e a uma escala diferente, que pode contribuir, ainda que de forma grosseira, para a percepção do comportamento atractivo e/ou repulsivo manifestado por cada uma das ilhas, durante os períodos observados.

Desde logo, parece não existir uma relação directa entre a tendência de decréscimo populacional que tem vindo a ser testemunhada nalgumas das ilhas mais pequenas do Arquipélago e a sua propensão em termos de movimentos internos. Se atendermos àquelas que, ao longo das últimas três décadas, encetaram um percurso descendente, no que respeita ao volume dos efectivos aí fixados (e se exceptuarmos o caso de Santa Maria, cujo comportamento é marcadamente repulsivo ao longo do tempo), verificamos que existem casos em que acabam, gradualmente, por vir a demonstrar algum poder de atracção interna de que antes não dispunham. A ilha Graciosa ilustra bem uma situação deste tipo, revelando uma tendência repulsiva ao longo dos anos setenta e oitenta que se altera na segunda metade da década de noventa. $\mathrm{O}$ mesmo se passa, ainda, em relação à ilha das Flores.

Podemos destacar ainda uma outra situação, respeitante às ilhas de $\mathrm{S}$. Miguel, Terceira, Pico e S. Jorge. Qualquer uma destas apresenta um comportamento bipolarizado e consistente no tempo, se considerarmos os três maiores períodos de referência para cada uma das décadas em observação (1973-81, 1985-91 e 1995-01). Significa isto que elas combinam, simultaneamente, concelhos de saída e de entrada, formando assim dois grandes "blocos" contrastantes, em termos das tendências migratórias demonstradas. Em S. Jorge, a Calheta permaneceu, ao longo de quase trinta anos, como um concelho, predominantemente, de "saída", por oposição ao das Velas. Na situação em que, durante esse período, se encontrou o Pico (a de progressiva perda de população residente), as Lajes nunca apresentaram um saldo migratório de sinal positivo, contrariamente ao que aconteceu com os concelhos de Madalena e S. Roque. Em relação à ilha Terceira, Angra do Heroísmo tem vindo a apresentar-se como um concelho de repulsão, enquanto a Praia da Vitória demonstra uma clara tendência atractiva. Por fim, em S. Miguel, somos confrontados com a progressiva manutenção de saldos positivos, e de significativo peso relativo, por parte de Lagoa, ao mesmo tempo que Vila Franca do Campo e Povoação insistem em apuramentos migratórios de sinal contrário.

\footnotetext{
${ }^{5}$ Como sublinha J. M. Malheiros, "este Portugal, tendencialmente pós-moderno e pós-fordista, viu acentuar-se a complexidade dos movimentos migratórios internos na década de 90 (...)” (Malheiros, 2002: 122).
} 
Quadro 1 - Saldo migratório interno e taxas dos saldos migratórios internos, por concelhos

\begin{tabular}{|c|c|c|c|c|c|c|c|c|}
\hline \multirow[b]{2}{*}{ CONCELHOS } & \multicolumn{2}{|c|}{ 1973-81 } & \multicolumn{2}{|c|}{ 1985-91 } & \multirow{2}{*}{$\begin{array}{l}\text { TCAM da } \\
\text { população } \\
\text { entre } \\
1981-91 \\
(\%)\end{array}$} & \multicolumn{2}{|c|}{ 1995-01 } & \multirow{2}{*}{$\begin{array}{c}\text { TCAM da } \\
\text { população } \\
\text { entre } \\
1991-01 \\
(\%)\end{array}$} \\
\hline & SMI & $\begin{array}{l}\text { TSMI } \\
(\%) \\
\text { (Média } \\
\text { anual) }\end{array}$ & SMI & $\begin{array}{l}\text { TSMI } \\
(\%) \\
\text { (Média } \\
\text { anual) }\end{array}$ & & SMI & $\begin{array}{l}\text { TSMI } \\
(\%) \\
\text { (Média } \\
\text { anual) }\end{array}$ & \\
\hline Vila do Porto (Sta. Maria) & -232 & $-0,49$ & -123 & $-0,39$ & $-0,93$ & -29 & $-0,10$ & $-0,60$ \\
\hline Lagoa (S. Miguel) & 351 & 0,37 & 442 & 0,65 & 0,04 & 528 & 0,71 & 0,91 \\
\hline Nordeste (S. Miguel) & 3 & 0,01 & -87 & $-0,30$ & $-2,12$ & 43 & 0,15 & $-0,37$ \\
\hline Ponta Delgada (S. Miguel) & 321 & 0,07 & -302 & $-0,09$ & $-0,29$ & -1610 & $-0,46$ & 0,61 \\
\hline Povoação (S. Miguel) & -13 & $-0,02$ & -57 & $-0,15$ & $-1,43$ & -17 & $-0,05$ & $-0,85$ \\
\hline Ribeira Grande (S. Miguel) & -36 & $-0,02$ & 108 & 0,08 & $-0,35$ & 377 & 0,25 & 0,47 \\
\hline V. F. do Campo (S. Miguel) & -102 & $-0,12$ & -98 & $-0,17$ & $-0,71$ & -119 & $-0,20$ & 0,09 \\
\hline Angra do Heroísmo (Terceira) & -45 & $-0,02$ & -59 & $-0,03$ & 0,73 & -308 & $-0,16$ & 0,09 \\
\hline Praia da Vitória (Terceira) & 570 & 0,38 & 11 & 0,01 & $-0,16$ & 253 & 0,24 & $-0,09$ \\
\hline Santa Cruz (Graciosa) & -38 & $-0,10$ & -45 & $-0,16$ & $-0,36$ & 126 & 0,50 & $-0,82$ \\
\hline Calheta (S. Jorge) & -208 & $-0,64$ & -98 & $-0,41$ & 0,17 & -82 & $-0,38$ & $-1,03$ \\
\hline Velas (S. Jorge) & 144 & 0,33 & 45 & 0,15 & $-0,38$ & 99 & 0,33 & $-0,18$ \\
\hline Lajes (Pico) & -81 & $-0,19$ & -117 & $-0,40$ & $-0,46$ & -74 & $-0,28$ & $-0,98$ \\
\hline Madalena (Pico) & 84 & 0,19 & 56 & 0,18 & $-0,02$ & 139 & 0,43 & 0,28 \\
\hline S. Roque (Pico) & 120 & 0,45 & 66 & 0,34 & $-0,01$ & 100 & 0,52 & $-0,13$ \\
\hline Horta (Faial) & 160 & 0,14 & 65 & 0,08 & $-0,37$ & 87 & 0,11 & 0,10 \\
\hline Lajes (Flores) & -48 & $-0,35$ & 6 & 0,07 & $-1,08$ & 3 & 0,04 & $-1,24$ \\
\hline Santa Cruz (Flores) & 25 & 0,14 & 44 & 0,32 & 0,68 & 103 & 0,78 & $-0,53$ \\
\hline Vila N. do Corvo (Corvo) & -19 & $-0,70$ & -47 & $-2,26$ & 0,60 & 29 & 1,29 & 0,79 \\
\hline
\end{tabular}

Fonte: INE, Recenseamentos da População, 1981, 1991 e 2001.

A coexistência, na mesma ilha, de concelhos eminentemente atractivos com outros marcadamente repulsivos reflecte, por si só, assimetrias internas de ordem bastante variada, e de explicação nem sempre fácil. Porém, no caso concreto de S. Miguel - ilha onde se encontra fixada mais de metade da população do Arquipélago - essas desigualdades tenderão a assumir uma relação directa com os processos de crescimento e de recomposição interna encetado pelo principal núcleo urbano - Ponta Delgada. Alguma investigação já existente sobre as dinâmicas de ocupação espacial e de densificação urbana no concelho onde este se insere, aponta para a interferência de determinadas lógicas de mobilidade interna quer no aumento populacional significativo que o município em causa registou, durante a última década do século passado, quer na recomposição da sua área urbana (Ferreira, 2005). Com efeito, o alastramento da "mancha" urbana mais antiga e o consequente reforço demográfico do seu "anel" circundante, se, por um lado, indiciam movimentos de centrifugação de efectivos originários do "casco velho" da cidade, por outro lado, sugerem a fixação permanente de população vinda de outros concelhos. Este segundo vector é, de resto, aquele que vai ao encontro do ponto em análise, uma vez que se insere nas observações anteriores em que aos municípios que não beneficiam da contiguidade espacial ao de Ponta Delgada estão, quase sempre, associados saldos migratórios internos de sinal negativo.

De uma forma resumida, podemos dizer que as transformações na mobilidade passaram, em grande parte, pelo reforço da terciarização da economia açoriana, através, designadamente, da implantação de um leque bastante diverso de serviços de natureza económica, alguns deles consubstanciando-se em filiais e sucursais de empresas nacionais (Fortuna e Couto, 1997; Santos, 1995); pelo maior peso do subsector da Construção e a expansão das Obras Públicas, com a instalação, na Região, de empresas sedeadas no Continente e a consequente transferência de recursos humanos (quadros e operários); pelo aumento da empregabilidade feminina; pelas maiores facilidades de comunicação e circulação de pessoas e famílias, que beneficiam, fundamentalmente, as ilhas com maiores possibilidades de dinamização da economia. Demograficamente mais 
jovens vêem o envelhecimento atenuar-se por via da maior atractividade de imigrantes e dentro destes dos mais qualificados, compensando, de algum modo, a entrada de emigrantes regressados, com perfis distintos, o que não acontece nas ilhas mais pequenas e desertificadas.

No que se refere às saídas, em especial as respeitantes aos movimentos internos, torna-se difícil identificar, uma lista de factores que consigam fornecer pistas para a explicação da tendência repulsiva demonstrada pela Região, em especial ao longo dos anos noventa. Estamos em crer que uma parte substancial destes movimentos terá ficado a dever-se, por um lado, ao regresso de pessoas ao local original de residência (à luz, por exemplo, dos movimentos circulares anteriormente descritos); e, por outro lado, ao aumento dos fluxos de estudantes em direcção ao Continente, sem contrapartida idêntica nas entradas, como inicialmente acontecia. Todavia, é importante frisar que alguns dos grandes vectores que se encontram implícitos no conjunto de causas para o aumento das entradas, tenderão, igualmente, a ser válidos para as saídas, como, por exemplo, o reforço da flexibilidade e precariedade da mão-de-obra e a maior integração dos mercados regionais, ambos promotores do incremento da mobilidade de trabalhadores (Malheiros, 2002:122). Neste sentido, também as ilhas com menor número de habitantes e maior nível de envelhecimento populacional surgem mais penalizadas na sua atractividade demográfica.

\section{$* * *$}

Entre mundos e continentes diversos, que se aproximam ou afastam - da América à Europa e a África - os Açores, com centralidades e periferias distintas (Rocha et al., 2005), apresentam, simultaneamente, rupturas e continuidades nas tendências migratórias, de atracção e repulsão populacional, que ajudam a definir as características das suas principais unidades territoriais - as ilhas. É, ainda, importante notar que são também as fragilidades e potencialidades de cada uma delas - e, por vezes, do Arquipélago no seu todo - a alimentar estas mesmas lógicas de atracção e de repulsão, as quais, como se compreende, se encontram diferentemente associadas a cada um dos tipos de movimentos migratórios analisados.

Actualmente, os mercados de trabalho ao nível de ilha, à luz da grande diversidade das suas condições e do seu leque de oferta, parecem jogar um papel determinante na captação, ou não, de migrantes. Através da capacidade de fazer convergir para si a maior parte quer dos fluxos imigratórios quer dos movimentos internos - extensíveis, inclusive, ao território continental -, um número relativamente reduzido desses territórios insulares tem conseguido fixar, numa lógica de acumulação, população com um perfil mais jovem e qualificado.

Neste sentido, S. Miguel, Terceira e Faial continuam a apresentar uma natureza essencialmente nodal, pois não só têm atraído volumes consideráveis de efectivos, como a sua capacidade emissora encontra-se posta em evidência quando atendemos ao papel que desempenham dentro de alguns movimentos de circulação. Em sentido inverso, e ainda que de forma distinta, podemos arriscar dizer que as restantes ilhas continuam a debater-se com a impossibilidade de experimentarem mudanças significativas na sua estrutura demográfica - ao ponto, por exemplo, de não verem atenuada a tendência de envelhecimento -, somando a isto, ainda, o perigo da cristalização continuada da sua estrutura económica e social.

Dentro deste quadro de acentuadas diferenças socioterritoriais, o carácter marginal deste segundo grupo de ilhas - e de entre as quais se destacam Santa Maria, Graciosa e S. Jorge -, resulta tanto da sua falta de capacidade de atracção, como do esvaziamento populacional testemunhado ao longo das últimas duas ou três décadas, factores que, de forma alguma, têm sido compensados pela via dos fluxos de regresso. De resto, e tendo em conta o perfil essencialmente envelhecido e pouco qualificado, da população de emigrantes que, nos últimos anos, regressaram aos Açores, o impacte positivo deste movimento em particular na estrutura demográfica, social e económica de cada uma das ilhas do arquipélago, tenderá sempre a assumir proporções reduzidas.

Neste contexto, as ilhas, os seus futuros mais imediatos, são (e sê-lo-ão cada vez mais) o que forem a intensidade das entradas e das saídas da população e dos seus perfis. Para trás ficou o suporte tradicional de um movimento natural, com uma forte intensidade da natalidade e da mortalidade, que ainda hoje justifica a existência de estruturas demográficas bem diferenciadas, nas quais preponderam diferentes níveis de envelhecimento populacional, apesar de, é certo, este ser também reflexo da interferência de mobilidades passadas, nas quais a emigração jogou um importante papel diferenciador. 


\section{Bibliografia}

ANCKAR, D. (2006), "Islandness or smallness? A comparative look at political institutions in small islands states", Island Studies Journal, vol 1, n. ${ }^{\circ}$ 1, pp. 43-54.

BALDACCHINO, G. (2004), "The coming of age of islands studies", Tijdschrift voor Economiche en Sociale Geografie, vol. 95 , n. ${ }^{\circ} 3$, pp. $272-283$.

BALDACCHINO, G. (2006), "Islands, Islands Studies, Island Studies Journal”, Island Studies Journal, vol. 1, n. ${ }^{\circ}$ 1, pp. 3-18.

BALDACCHINO, G. (Ed.) (2007), A World of Islands, Charlottetown, University of Prince Edward Island, Institute of Island Studies.

BERTRAM, G. e POIRINE, B. (2007), "Islands and political economy", in Baldacchino, G. (Ed.), A World of Islands, Charlottetown, University of Prince Edward Island, Institute of Island Studies, pp. 325-377.

BERTRAM, G. \& WATTERS, R. F. (1985), "The MIRAB economy in the South Pacific microstates", Pacific Viewpoint, vol. 26, n. $^{\circ} 3$, pp. 497-520.

CHAPMAN, M. (1991), "Pacific island movement and socioeconomic change: metaphors of misunderstanding", Population and Development Review, Vol. 17, n. ${ }^{\circ}$ 2, pp. 263-292.

DIOGO, F., TOMÁS, L. e MEDEIROS, O. (1996), “A população estudantil da Universidade dos Açores: contributo para um estudo de desenvolvimento local", Arquipélago-Ciências Sociais, n. ${ }^{\circ}$ 9-10, Ponta Delgada, Universidade dos Açores, pp. 19-58.

DOCQUIER, F. e SCHIFF, M. (2006), "Measuring Skilled Emigration Rates: The Case of Small States", IZA Discussion Paper No. 3388 (Available at SSRN: http://ssrn.com/abs tract $=1294535$ or doi:10.1111/j.0042-7092.2007.00700.x).

FAIRBAIRN, Te'o I. J. (2007), "Economic vulnerability and resilience of small island states", Island Studies Journal, Vol. 2 , n. ${ }^{\circ} 1$, pp. $133-140$

FERREIRA, E. (2005), Crescimento Urbano, Heterogeneidade Social e Coexistência Residencial. O caso da freguesia de Santa Clara no contexto do concelho de Ponta Delgada (1981-2001), trabalho de síntese no âmbito de provas de APCC, Ponta Delgada, Universidade dos Açores (policopiado).

FORTUNA, M. e COUTO, J. P. (1997), Desenvolvimento, Autonomia e Equilíbrio das Finanças Públicas. O problema dos Açores na nova era autonómica, Ponta Delgada, Universidade dos Açores.

GONÇALVES, R. L. (2010), "Migrações e espaço de oportunidade: uma reflexão sociológica" in Actas da Conferência Internacional Aproximando Mundos: Emigração, Imigração e Desenvolvimento em Espaços Insulares, Lisboa, Fundação Luso-Americana para o Desenvolvimento (FLAD), pp. 301-326.

INE, Recenseamento Geral da População, 1981, 1991 e 2001.

KING, R. (1999), "Islands and migration", in Biagini, E e Hoyle, B. (Eds.), Insularity and Development - International Perspectives on Islands, London, Pinter, pp. 93-115.

KING, R. (2010), "A geografia, as ilhas e as migracõoes numa era de mobilidade global", in Actas da Conferência Internaciona Aproximando Mundos: Emigração, Imigração e Desenvolvimento em Espaços Insulares, Lisboa, Fundação Luso-Americana para o Desenvolvimento (FLAD), pp. 27-62.
KING, R. e CONNEL, J. (Eds.) (1999), Small Worlds, Global Lives - Islands and Migration, London, Pinter.

MALHEIROS, J. (2002), "Migracões", in Medeiros, C. A. (Dir.), Geografia de Portugal, Vol. 2, Lisboa, Círculo de Leitores.

OBERST, A. e McELROY, J. L. (2007), "Contrasting socioeconomic and demographic profiles of two small island economy species: MIRAB versus PROFIT-SITE", Island Studies Journal, vol. 2, n. ${ }^{\circ} 2$, pp. 163-176.

PEIXOTO, J. (1998), "Selectividade migratória e dinâmicas regionais: as migracões inter-regionais em Portugal nos anos 80", Revista de Estatística, $3 .^{\circ}$ QUAD 98, n. ${ }^{\circ}$ 9, Instituto Nacional de Estatística, pp. 73-112.

PIRES, R. P. (2003), Migrações e Integração, Oeiras, Celta Editora.

RATTER, B.M.W. e SANDNER G. (1996), "Small islands, large questions", Geographische Zeitschrift, vol. 84, n. ${ }^{\circ}$ 2, pp. 63-66.

ROCHA, G. P. N. (1991), Dinâmica Populacional dos Açores no século XX - Unidade. Permanência. Diversidade, Ponta Delgada, Universidade dos Açores.

ROCHA, G. P. N. (2008), "Crescimento da população e os novos destinos da emigração", in Matos, A. T., Meneses, A. de F. de e Leite, J. G. R. (Dirs.), História dos Açores, Vol. II, Angra do Heroísmo, Instituto Açoriano de Cultura, pp. 265-305.

ROCHA, G. P. N. e FERREIRA, E. (2008), "População e circulação de pessoas", in Matos, A. T., Meneses, A. de F. de e Leite, J. G. R. (Dirs.), História dos Açores, Vol. II, Angra do Heroísmo, Instituto Açoriano de Cultura, pp. 581-610.

ROCHA, G. P. N. e FERREIRA, E. (2009), "A emigração açoriana na segunda metade do século XX: algumas perspectivas da imprensa micaelense", in Actas do Colóquio Internacional A História da Imprensa e a Imprensa na História. O Contributo dos Açores, Ponta Delgada, Centro de Estudos Gaspar Frutuoso (Universidade dos Açores) - Centro de Estudos Interdisciplinares do Século XX (Universidade de Coimbra), pp. 183-201.

ROCHA, G. P. N., FERREIRA, E., MENDES, D. (no prelo), Emigração e Regresso aos Açores (estudo encomendado pela Presidência do Governo Regional dos Acores/Direccão Regional das Comunidades ao Centro de Estudos Sociais da Universidade dos Açores/CES-UA).

ROCHA, G. P. N., MEDEIROS, O. H. R., FERREIRA, E. (2009), Perfis e trajectórias dos imigrantes nos Acores, Ponta Delgada, Governo Regional dos Açores/ Direcção Regional das Comunidades.

ROCHA, G. P. N., RODRIGUES, J. D., MADEIRA, A. B., MONTEIRO, A. (2005), "Os Açores como região de fronteira", Arquipélago - História, 2. ${ }^{\text {a }}$ série, vol. IX, Ponta Delgada, Universidade dos Açores, pp. 105-140.

SEF, Estatísticas de Estrangeiros, 2001-2009.

SRAM, Plano Regional de Ordenamento do Território para a Região Autónoma dos Açores.

SREA, Anuário Estatístico da Região Autónoma dos Açores, vários.

SREA, Estimativas da População, 2008 e 2009.

WARRINGTON, E. e MILNE, D. (2007), "Island Governance", in Baldacchino, G. (Ed.), A World of Islands, Charlottetown, University of Prince Edward Island, Institute of Island Studies, pp. 379-427. 